\title{
The social dimension of industrial ecology: on the implications of the inherent nature of social phenomena
}

\author{
Walter J.V. Vermeulen \\ Department of Environmental Studies and Policies \\ Copernicus Institute for Sustainable Development and Innovation \\ Utrecht University \\ P.O. Box 80115, NL - 3508 TC Utrecht, The Netherlands \\ E-mail: w.vermeulen@geo.uu.nl
}

\begin{abstract}
A substantial body of scientific literature has grown on the necessity, opportunities and attractiveness of industrial ecology strategies. In many cases, proponents claim combined ecological and economic gains. Yet, mainstreaming of industrial ecology practices shows slow progress. Theorists often use a simplified model of an actor's behaviour in society, stressing a 'single actor rational choice' approach. Yet, they have proposed innovations that imply social processes going far beyond this model. They involve processes of multiactor cooperation, divergence in actor group characteristics and interactions among various domains of society (state, science, production, civil society and people). In this paper my central position is that proper understanding of these social phenomena is essential in understanding the (slow) progress in mainstreaming industrial ecology. This calls for a more central role of an empirical retrospective social science analysis, as demonstrated with cases in the fields of eco-industrial park development, and innovation and sustainable building.
\end{abstract}

Keywords: social theory; society; industrial ecology; implementation.

Reference to this paper should be made as follows: Vermeulen, W.J.V. (2006) 'The social dimension of industrial ecology: on the implications of the inherent nature of social phenomena', Progress in Industrial Ecology - An International Journal, Vol. 3, No. 6, pp.574-598.

Biographical notes: Walter J.V. Vermeulen is Associate Professor in the field of governance of sustainable production and consumption at the Department of Environmental Studies and Policies, Institute for Sustainable Development and Innovation, Utrecht University.

\section{Introduction}

In nearly two decades, industrial ecology has become an established academic school, with growing numbers of books and articles, various dedicated international journals, reflections upon its history (Erkman, 1997; Graedel, 2000; Erkman, 2002; Fisher-Kowalski, 2002) and academic societies (e.g., the International Society for 
Industrial Ecology). Much work has been done in analysing the current state of affairs, theorising and developing methodologies. Natural scientists have played a dominant role, which is quite understandable, industrial ecology having its origins in ecology, engineering and even partly the business community. Although some of the definitions include a social science perspective (White, 1994), the input of social sciences has been rather poor. This is actually a remarkable situation, as the very core subject of industrial ecology is the redesign of society, originally inspired by ecosystem metaphors! It is hard to understand how this assignment can be fulfilled without the input of social sciences. I firmly believe that this input is essential even to the further development and application in practice of the solutions proposed by industrial ecologists. To stress this, the application of the concept of eco-industrial parks may serve as an example: this challenging concept, exemplified by the Kalundborg case, echoed endless times since the early days of industrial ecology, seems to have great birth problems in reality. It has been embraced in The Netherlands, with about ten years of government support programmes. Yet in practice only a few examples of exchanges of materials or energy in practice can be found. The same goes for the USA: state-sponsored cases started working in the mid-1990s. However, recently I was very disappointed in looking for examples of practical application in Cohen-Rosenthal's 2003 book Eco-industrial Strategies. Looking at US case studies, which we ourselves studied (Heeres et al., 2004) about five years earlier, there was still no evidence of businesses actually being involved in application in these cases!

Here we see a form of slow progress, which can be witnessed for various types of eco-innovations: after initially strongly supported illustrative cases of first movers, mainstreaming turns out to be a very hard job. Some may blame businesses pursuing self-interests (Ayres, 1989), or societies, "particularly democratic societies, having messy social controls, taking long time to establish them and often poorly implementing them" (Ehrenfeld, 2000, p.231).

My argument in this paper is that social scientists should take a more prominent role in industrial ecology. Social science has been given a rather instrumental role ("tell us how to implement it" - Graedel and Allenby, 1995), instead of being brought to the core of the issue: the transformation of society. In this paper, I will show that industrial ecology rests upon oversimplified models of society.

These oversimplified models may be a crucial obstacle to the mainstreaming of eco-industrial practices. As some others have done before (Stern, 1993; Cohen-Rosenthal, 2000; Boons and Roome, 2001; Erkman, 2002; Korhonen, 2004), I call for a debate and theory development on the social dimension of industrial ecology. I will use some of my earlier research work to make a charcoal drawing of such a theory, in response to the often implicit images of society in industrial ecology literature.

In the following sections, I will first discuss industrial ecology's metaphors and their implications. Then I will briefly discuss the implicit image of society in some classic industrial ecology texts and then put my argument in the broader context of a debate within industrial ecology about prescriptive versus descriptive science. After this I will shift to a social science perspective and briefly present relevant elements for the analysis of processes of societal change. In Sections 7 and 8, I will present two cases as illustration, finally concluding with a reflection on the future challenges for analysing the social dimension of industrial ecology. 


\section{Following the metaphors}

Industrial ecology has often been described as the world of metaphors. The metaphors have one thing in common: they all carry the 'imitation imperative'. Looking at the perfection of nature and the failures of modern society, all metaphors cry out, "Copy society from nature". Metaphors from ecology inspiring industrial ecologists include:

- Closed food webs - one species uses the excrements of other species, a phenomenon that used to be non-existent in human society: in nature, scavengers are highly valued in contrast to their societal equivalents (Ayres, 1989; Ehrenfeld, 2000, p.238)

- Eco-systems as cooperating closed food system - at a higher level of aggregation, eco-systems are balanced systems of interlinked animals and plants in specific physical, geomorphologic, climatic and eco-hydrologic circumstances, and thus are modelled as stable systems, which are to be imitated by human society (see, for example, Frosch and Gallopoulos, 1989)

- Cascading - high (energy)-value forms of use of organic waste are succeeded by low-value forms of (re)use (Ehrenfeld, 1997)

- Symbiosis - the close cohabitation of very different species to each other's mutual benefit (Frosch and Gallopoulos, 1989, p.126)

- The exclusive use of solar energy in ecosystems (in photosynthesis) (Ayres, 1989; Tibbs, 1991; Graedel and Allenby, 1995).

A common feature in these ecological metaphors is that the systems use resources without disturbing the balance or equilibrium in the system and thus provide a sustainable use of the environment, which is used as the inspiration for the redesign of society. The mix of metaphors can be summarised into the image of the recycling society, reducing its use of virgin resources.

The common message is the assignment to move from what is called linear Type I ecology (with unlimited output of waste from the social system) towards Type III ecology (with closed cyclic material flows) (Socolow, 1994, p.25; Graedel and Allenby, 1995, p.95; Lifset and Graedel, 2002; Korhonen, 2004).

Some of the metaphors inspiring industrial ecologists go beyond these linkages and cycles, such as Ayres (1989) using photosynthesis as the metaphor for modern technologies in new production processes. All the metaphors mentioned here in essence describe physical entities or processes, thus still remaining in the field of natural sciences and engineering, yet state that human beings should copy those physical processes in their productive (read: physical) activities.

Yet some even go beyond this line, using metaphors to describe the social organisation in nature, e.g., ecosystem, and thus setting them as an example for society. In this way, Ehrenfeld (2000, p.238) has been describing the connectedness, sense of community and cooperation, and limited competition in ecosystems as a model for society. Ignoring the reasonable critics on this harmonic view of ecosystems (Andrews, 2001, p.41), for the argument here it is important to recognise that presenting this metaphor as the desired situation implies an opposite image of the current society: one of non-connectedness, individualism and competition. Before we run into a discussion of this image, we first need to have a closer look at what industrial ecology actually expects to be changed in society. 


\section{Implications of industrial ecology: redesigning physical flows}

Looking at the practical implications suggested in the industrial ecology literature, we see an agenda with at least six typical types of changes in modes of producing goods for society. Looking at the form of presentation of this agenda, in terms of changed physical and material flows and applied processes, it is very much an agenda for engineers and natural scientists, and clearly in the context of industrial production, although it may involve consumer behaviour as well.

These changes are guided by definitions and prescriptions of the end goals or end state of sustainable production (Daly, 1990; Graedel and Allenby, 1995; Ehrenfeld, 2000). The six main items on the industrial ecology application agenda are:

1 the redesign of production processes into low- or zero-emission systems

2 the redesign of the full life cycle of products into minimal-impact human-needs-satisfying systems

3 as a special field of Item 2: the (re)design of the built environment into minimal-impact-producing infrastructures

4 the creation of recycling systems for material flows after the use of resources or products

5 the creation of regional networks of material exchange

6 at the resource site: the redesign of society's energy system into a system based on renewable resources with low impact.

The first agenda item, redesigning production processes, actually was not the first issue suggested in industrial ecology, but it has been argued frequently that industrial ecology very well links to the field of cleaner production (Huisingh and Bailey, 1982; Huisingh et al., 1986), transitions to zero-emission systems and the application of new production technologies (such as green chemistry, osmosis, closed water systems in production processes), with industrial ecology going a step further than the other fields (Graedel and Allenby, 1995).

Pollution prevention strategies and practices (late 1980s, 1990s) have made a case for industry's efforts in research and development in environmental innovations, enabling improved environmental and economic performance of industries. Though the pollution prevention strategy has been promoted and applied widely, in practice many are still to take first steps on this agenda (Cagno et al., 2005).

A special case in this respect is the broadening of the search area, shifting from intrafirm production processes to searching for improvements in the entire production chain (labelled as life cycle management, supply chain management or integrated chain management), looking for various options for improvement, such as change of inputs, change of processes and composition of products, and addressing consumption and post-consumption phases (Quakernaat and Weenk, 1993; Vermeulen et al., 1994; Cramer, 1996; Wolters et al., 1997; Ytterhus et al., 1999; Kogg, 2003; Vermeulen and Ras, 2006). 
This brings us to the second item on the agenda, the redesigning of products. Various dedicated strategies have been suggested, such as designing for recycling (Graedel and Allenby, 1995), for reducing material use (Ehrenfeld, 2000) and for low energy use during the consumer phase (Graedel and Allenby, 1995). Inclusive approaches are all environmental aspects, full life cycle and even beyond that: rethinking existing product concepts and providing other forms to satisfy human needs (product services systems, function innovations) (Mann and Jones, 2002). Again there is a great role for environmental innovations.

As a special case of redesigning products, we can present the third item: the (re)design of the built environment. This includes redesigning not only individual buildings like dwellings or utility buildings, but also the level of regional infrastructures (housing quarters, industrial parks) and regional systems of transportation (roads, railways, etc.). Applying low-impact materials, allowing for the reuse of demolition waste, the use of passive solar energy and new renewable energy technologies in buildings, conservation of ecosystem elements in rural areas - all are examples of this (Anink et al., 1996; Grant, 1997).

The fourth item focuses on the waste side: the end point of the Type I ecology, where the 'bending work' needs to be done: the closing of material cycles by the creation of recycling systems. This is clearly a mix of technological challenges and social change. We have seen discussions on the appropriate scale for recycling systems (national, regional, local) (Sterr and Ott, 2004). In the old text of Frosch and Gallopoulos (1989) these are designed as national markets for secondary materials. Ayres and Ayres (1996, p.8) describe recycling strategies for all main material flows, applying mixes of recycling strategies (reuse, repair, remanufacture, waste mining). Others also suggest dematerialisation and substitution (Graedel and Allenby, 1995). As an additional opportunity, we also see in early writings suggestions for creating forms of 'symbiosis' between firms (Frosch and Gallopoulos, 1989), implying the exchange of waste material or energy from one firm to a neighbouring firm, thus reducing waste-depositing costs for the one and reducing costs of material or energy inputs for the other.

The fifth item on the agenda aggregates various such symbioses into regional networks of material exchanges: the creation of eco-industrial parks, regional networks and recycling networks (Tibbs, 1991). This was promoted by Ayres and Ayres, who also discussed examples and prerequisites, like the need to have at least some large industries (like a primary raw material producer, a refiner or a waste recycler) around which an eco-industrial park can be 'organised' (Ayres and Ayres, 1996, p.373). Others, like Coté and Cohen-Rosenthal and Musnikow, have done much work in describing possible forms of cooperation at eco-industrial parks and in developing strategies for implementation, following the model of Kalundborg (Cote, 1997; Cohen-Rosenthal and Musnikow, 2003).

The sixth and last item on the industrial ecology agenda is redesigning the energy system: increasing efficiency of use (Graedel and Allenby, 1995, p.300) and making the transition to various forms of renewable energy (Korhonen, 2001).

Looking at these six agenda items, we have to add the observation that they are not mutually exclusive. For example, strategies for eco-industrial parks may very well include Items 3, 4 and 6 . The agenda also addresses various levels of aggregation, sometimes a firm, or firm-to-firm relations, and sometimes the regional or national level (Erkman, 2002). In addition to this, looking from a social science perspective, we can identify at least six implications as cross-cutting themes, linking these agenda items: 
1 The first implication is that it is about firms changing from linear routine practices (linear from resource use to waste disposal) focusing on short-term profits in business management (only focusing on the financial bottom line and stockholder interests) into multi-goal-oriented strategies (aiming for corporate socially responsible business practices). Various scholars, not necessarily originating from the field of industrial ecology, have developed approaches for redirecting management orientations, accounting for the 'triple bottom line: Planet, People, Profit' (Elkington, 1994), setting 'the Natural Step' (Nattrass and Altomare, 1999; Robèrt, 2000) and seeing the (non-obvious) opportunities of clean production.

2 The second implication is that of firms accepting and using (processed, former) waste streams. This is often portrayed in industrial ecology as an obvious and often cost-saving solution to many problems (Ayres and Ayres, 1996, p.290).

3 The third implication is that we should not analyse the implementation of industrial ecology as a single-actor activity, but as forms of multi-actor cooperation. The redesign of production processes will require cooperation with equipment suppliers; life cycle management requires close cooperation with suppliers and customers. The redesign of products implies cooperation with suppliers of product parts and organisation of recollection and reuse systems. The development of sustainable product services systems implies the involvement of service-oriented businesses outside the sphere of industrial production. The (re)design of the built infrastructure is a cooperative process with many actors. And, as a last example, eco-industrial parks imply close cooperation between neighbouring firms that would normally live together without interaction, and the creation of recycling systems that connect businesses, consumers and others that previously would not even meet each other.

4 The fourth implication is that implementation of industrial ecology mostly implies process innovation and adoption. These processes cannot be understood if they are pictured as a single-actor activity. They are by nature interactions between inventors, government support agencies, firms adjusting the invention into marketable goods and, finally, potential adopters.

5 The fifth implication is that implementation of industrial ecology implies simultaneous processes all addressing the same actors. If we shift our perspective towards that of individual firms that are addressed by the industrial ecology agenda, we can see that they are accosted with all these issues and also other societal demands simultaneously.

6 The sixth implication is that of mutual competition between these items. Governments may develop aggregate policies, enhancing the implementation of all these items simultaneously. But if we shift our focus to the level of individual firms, we need to acknowledge their constraints. Within limited budgets and personal capacities, choices will need to be made by firms. Thus they may rationally choose the less uncertain and the less time-consuming options. Some of the items may even be conflicting, such as organising recycling and reuse of materials currently in use (Items 4 and 5), or developing new products with different materials (Items 1 and 2). 
Industrial ecology literature hardly reflects on these implications. By far the largest part of industrial ecology literature deals with the development and application of various methods for measuring environmental impacts of human production and consumption (such as applications of Life Cycle Assessment (LCA) and Substance Flow Analysis (SFA); material budgets; assessing options) (Graedel and Allenby, 1995) and describing practical cases of products, materials and eco-industrial regions. Some of the literature discuss management methods for introducing industrial ecology items and possible policies (Socolow, 1994).

Only a few go beyond this, for example discussing connected world views and ethical issues (Ehrenfeld, 2000). But attention on the societal dimension is still scarce. As an exception, White has taken the social dimension as an element of the definition of industrial ecology, phrasing it as "the study of flows of materials and energy, and of the influences of economic, political, regulatory, and social factors on the flow, use and transformation of resources" (White, 1994).

\section{Industrial ecologist's image of society and behaviour}

As stressed in the first section, the analysis of society is crucial, as the core task of industrial ecology is the transformation of society. This implies two types of knowledge: first of all, a proper understanding of how societies function and how that may lead to environmental degradation; second, how do processes of change in society work and, using this knowledge, what can be said about programmes for implementing the suggested solutions, addressing various domains of society (politics, business, science, civil society, etc.)?

Looking for answers to these questions in various key publications on industrial ecology (Ayres, 1989; Frosch and Gallopoulos, 1989; Tibbs, 1991; Allenby, 1992; Ehrenfeld, 1992; Frosch, 1992; Graedel and Allenby, 1995; Ayres and Ayres, 1996) teaches us that images of society are often rather implicit, but play an important role in the argumentation. Often, these questions are not addressed directly, but texts may contain suggestions and advice about how to implement things. These pieces of advice mirror ideas about how actors in society can be influenced.

From the literature, we can extract a dominant model of thought about the social dimension: the image of society as a collection of rational-acting nuclei. This dominant image may be supplemented with some other images, such as social actors responding to society's demands ("Society demands $\rightarrow$ business brings it about") or an Enlightenment version of a society consisting of learning social actors, but these versions do not challenge the argument to be made here.

If we try to identify the dominant image of society in industrial ecology as a collection of rational-acting nuclei, we see that attention on the social dimension has not completely been lacking. For example, in one of the earliest writings, Ayres (1989) discusses causes of environmental disruption mainly in terms of market failure, saying: "residuals tend to disappear from the 'market' domain, where everything has a price, but not from the real world in which the economic system is embedded" (pp.365-366). Bringing up the popular allegory of the 'Tragedy of the Commons', he stresses the image of individuals pursuing their short-term self-interest without proper coordination either by the market or the state. ${ }^{1}$ He discusses economists' efforts to design and implement 
systems of price corrections. At the end of this early writing, his solution was, "the short sighted under-pricing of environmental and exhaustible resources must be stopped" (Ayres, 1989, p.371). In achieving this, he suggests a strong mandatory regulating role of governments in combination with market-oriented policy instruments. This image of the market and necessary adjustments can also be found in more recent work: in discussing the use of nitrogen-based chemicals, he concludes:

"but if relative prices of N-chemicals were to rise gradually (vis-à-vis human labour) over a long period of time, the end result would eventually occur automatically through the agency of 'invisible hand' of the market. This change in relative prices is the domain of government. It can be accomplished through a combination of regulation and tax policy." (Ayres, 1989, pp.156-157)

The same recipe can be found in another classical text, Industrial Ecology: An Environmental Agenda for Industry (Tibbs, 1991), inspired ${ }^{2}$ by the Frosch and Gallopoulos 1989 article. After describing the technological options (as in Section 3) and the plea for translating it to business vocabulary, Tibbs (1991, p.22) briefly discusses policy implications, also stressing placing a monetary price on environmental damage (Pigovian taxes), but also instruments like emission trading. Yet this text also contains evidence of a very optimistic faith in the creative forces of the market mechanism, as its hidden hand seems to be the hand of the magician. He says:

\footnotetext{
"historical data indicates that the industrial system shows evidence of 'regularities', predictably structured patterns of evolution and growth. These regularities essentially show that such things as the emergence of new technologies (...) have growth patterns that follow consistent and predictable S-shaped curves." (Tibbs, 1991, p.23)
}

Another author even more clearly building his argument on the image of a collection of egocentric-acting nuclei is Ehrenfeld. In his article, 'Industrial ecology: paradigm shift or normal science?' (2000), he argues that a different way of thinking and of seeing the world (or a new social paradigm) is needed. Though his reasoning should be seen merely as explicating a desirable world view, and not as social science, it clearly reveals an image of society in his description of the contemporary 'old' social paradigm. In this image, he places the economic man in the free market, coordinated by the invisible hand at the centre, in combination with individual autonomy, self-realisation, rational action, decision making and the use of Cartesian rationality (Ehrenfeld, 2000, pp.233-234). In his comparison between the existing old and the required new paradigm, Ehrenfeld adds another ecology-society metaphor: the sense of community and cooperation in ecosystems should also be copied into society, thus further stressing the image of society as a collection of selfish rational-acting nuclei (Ehrenfeld, 1992, pp.237-238).

Ayers and Ayers developed this point even further. In their 1996 book, they stress the need for "economies of integration": industrial ecosystems should at least "from the outside look like a single economic entity (firm)" (Ayres and Ayres, 1996, p.290). In their view, this might imply that producers, for example, 'must be induced to accept unfamiliar inputs (i.e., converted wastes)'. Discussing the pros and cons of various enforcement mechanisms of governing such clustered firms (like merging, cooperative system, keiretsu and others), they end with giving (local) public agencies a key role in influencing businesses in creating eco-industrial parks: the state has to help the hand of the market a bit. 
Although this image of the market is mostly presented as a constraint, some also give it a positive turn. The profitable Pollution Prevention Pays experiences are crucial to this view. Practice has taught that with proper attention, industries can identify gains in applying industrial ecology. By accepting this argument, the drawbacks of the image shift into an advantage, although some education may be needed, authors thus calling for wide teaching of the concepts (Frosch and Gallopoulos, 1989).

Others, such as Graedel and Allenby describe progress towards industrial ecology, starting from such win-win situations, even as the expected future. In describing the emergence of product-service systems, they present it as an inevitable development:

"Ultimately, corporations are likely to decide that, for large and/or complex products purchase no longer should be an option. (...) This situation (of take-back systems) will very likely become the standard mode of operation in the twenty-first century for all but the simplest products and consumables." (Graedel and Allenby, 1995, p.307)

As said before, in addition to this dominant image of society, some other supplementary images can be found, although they do not fundamentally distort the picture. An example is an image from society that goes beyond the individual actor in a market and portrays firms as social actors in a social context: they interact with society; their decision making is not just aimed at short-term cost-benefits, but also responds to the outside world. Of course, the first ones to be met in this outside world are the customers, but other actors (governments, science, NGOs) and firm's anticipation towards long-term developments may also be included in this image.

One clear example can be found in the early textbook of Graedel and Allenby. They argue that in particular, large firms - multinational corporations - respond to society. These firms listen to their customers and pick up signals from their business-to-consumer relations and business-to-business relations. The quality of responsiveness to society's demands is shown as a challenge for executives. Referring to the work of the Business Council for Sustainable Development, they show that multinational corporations increasingly perform in socially responsible ways and apply uniform standards throughout the world (Graedel and Allenby, 1995, p.296, p.299). My argument here is not to discuss the empirical evidence for this claim, but to show that this business <$>$ society responsiveness is suggested to make the business community the driving force in the change towards a sustainable society (Graedel and Allenby, 1995, p.293).

\section{Modes of sciences: from prescriptive normative towards descriptive analytical}

These rather simplified images of society in industrial ecology literature can be understood as one looks at the rise of industrial ecology as a field of knowledge. Erkman has described how industrial ecology has it roots in what we might call a symbiosis between ecologists and environmental (natural) scientists from academia and engineers from the industrial world, and how it has been taken up quite rapidly by academies of science in various countries and also by the UNEP (Erkman, 2002; Fisher-Kowalski, 2002). 
The metaphors from ecology offered a compelling mode of communication, giving a theoretical umbrella for practices emerging in industry in the 1980s and 1990s. As such, as described in the vocabulary of Tibbs's business-directed paper, it served as a powerful catalyst for bringing environmental issues into the business, political and research agenda.

The core of the assignment of industrial ecology is in describing the physical world, as the retrospective description of nature and its ecosystems serves as an example for retrospective description of material/physical flows in production and consumption systems in human society. In line with this focus, the very core of industrial ecology's work has been devoted to this, developing and improving SFA, LCA, etc., thus remaining in the domain of natural science-based methods and techniques.

But, as we showed in the previous section, industrial ecology has also partly, and mainly implicitly, been overturned by the very virtue of its metaphors, changing it from a retrospective, descriptive theory into a prescriptive, normative theory, suggesting societies should be redesigned, copying the features of nature, but without including a social scientific analysis of the human society!

We showed how implicit but oversimplified images of how society works have been part of industrial ecology thinking, resulting in a rather optimistic view of implementation. If we see society merely as a collection of economic rational nuclei, and we suggest that industrial ecology practices on the micro level are offering mutual gains for economy and ecology, and we stress the inevitable need and long-term collective interest, we cannot but expect that these economic rational nuclei will make the proper choices, sooner or later. They may need to be helped a bit on the cognitive level (supplying them with analytical tools and advice) and the motivational level (addressing them with economic incentives, and planning and management tools), and if that still does not work, a strong government must do the rest.

I am deliberately exaggerating to make this point clear, to stress the trust placed in the self-working power of natural science-based knowledge, and to stress that a necessary step in the thinking is obviously still missing. That is the step of a descriptive analytic social science approach to the processes of change (the second type of knowledge suggested at the start of Section 4), implementing the practices as advised by industrial ecology, thus moving from normative prescriptive inputs from social science towards a descriptive explanatory approach.

Various authors have been discussing a normative versus positive divide in industrial ecology (Korhonen, 2004, p.63). Lifset and Graedel argue that the tension between positive and normative is overstated, arguing that more normative work (they refer to the more practical design-oriented work of industrial ecology) is in the end based upon the more descriptive systemic analysis and resource studies in industrial ecology. In making this argument, they do refer to the role of social sciences, giving them the potential to help identify implementation strategies and the description and explanation of current production and consumption activities (Lifset and Graedel, 2002). But this refers to a rather restricted contribution of social sciences. This emphasis has led various commentators to propose "a new line of work in the field of industrial ecology focusing more on economical, political, regulatory, and cultural factors relevant for the implementation of this still promising concept" (Fischhoff and Small, 1999; Cohen-Rosenthal, 2000; Andrews, 2001; Erkman, 2002). 
In this paper, I suggest that the next step is a descriptive analytic social science approach to the processes of change, implementing the practices as advised by industrial ecology. In the early years of industrial ecology, this would not have made much sense, but as many countries by now have made substantial efforts in implementing the issues discussed in Section 3, we can now move towards an empirical analysis of such processes of societal change to sustainable production and consumption systems and use the results of such studies as a resource for a dedicated social science theory on the social dimension of industrial ecology.

\section{Social phenomena at three levels of society}

This brings us to turning the focus of industrial ecology from copying nature's physical characteristics into societal desiderata, towards a focus on a social theory of processes of change, implying the application of industrial ecology-derived practices. Making such a step implies entering a large field of connected social science disciplines with their many discourses and histories, such as sociology, business administration, management science, policy science, psychology, innovation science and more. These disciplines all have built-schools-of-environment-related studies. In the context of this paper, we can only give rough charcoal sketches, aiming to illustrate that the field beyond the notion of society as a collection of rational nuclei is a very rich field of theory and research practice to be further exploited.

Some have entered this field already. Esty and Porter (1998) have shown that industrial ecology does not always yield the suggested competitive advantage. Andrews (2001, p.41) has made critical remarks on the industrial ecology focus on individuals as rational, self-interested decision-makers, referring to transaction costs theory, cognitive limits, information problems, variance in strategies and the principal agent theory and stressing essential differences between individuals and organisations. His analysis, strongly leaning on economics, tends to focus on the micro level of society: that of individuals and individual organisations like firms. These are relevant elements of society, but to understand society, one also needs to address the meso level and the macro level with their own social phenomena and inherent nature.

The micro level of societies is made up of individual social actors. Many disputes of sociologists and psychologists have been on the relation between individual social actors and the society, with voluntaristic conceptions on one side and deterministic views on the other side. Nowadays, individual social actors are generally seen as self-learning actors within their social context (Giddens, 1993; Harré, 1993). Social actors adopt knowledge, explanations of the surrounding world and rules of conduct from this social context, thus constructing world views that enable them to cope with challenges from their surrounding world. Starting from early upbringing and continuing afterwards, people construct deep-rooted world views (including explicit and many implicit shared rules of conduct). The adoption of knowledge, explanations and rules is interactive and reflexive: individuals do not follow blindly, but in discourse with individual experiences and experiences supplied by society. These society-based experiences develop thanks to inputs of other social actors. Also, these society-based experiences are not homogeneous: individuals may be exposed to diverging world views and competing 
cultures, as described in a very challenging way by Schwarz and Thompson (1990). Yet on the level of practical life (at work, in households, leisure, etc.), social actors will often adopt rules of routines fitting such experience-based world views. Diverging from these social practices is possible, but may require a great deal of energy. To summarise this: it leads to an image of worldview-based routine-embedded reflexive social beings.

This implies that social actors are rational in their interaction with their surrounding society, but their world view-based routines can make them relatively inert. Yet this gives them advantages: routines reduce uncertainty, may enlarge efficiency, may be a way of coping with overloads of (diverging) information, etc. Actually, such shared experiences and practices contribute to social cohesion and a sense of community. ${ }^{3}$ From the perspective of change, however, they represent what innovation scientists have called 'locked-in' situations.

The concept of social actors, such as what I used now, refers to individual people. We need to distinguish them from organisations, which are forms of formalised cooperation between individuals (such as firms, governments, civil society organisations). As Andrews has stated, these cannot be conceptualised as identical to individual social beings. In addition to the sum of individuals active within an organisation, organisations are made up of additional social phenomena: the constituting relations between individuals, as structured by formal and informal rules (partly containing society-determined arrangements), powers, competences and obligations. At the level of the organisation as a whole cooperating individual, social actors determine specific organisational goals, but they do this within the context of these organisational features, and in interacting with and adapting to their societal surroundings. From the view of participating individual social actors, these goals and organisational settings define specified rules of conduct for their behaviour, in these cases 'locking them in' even more than at the individual level.

Describing the micro level as above links up already to the meso level of societies. This consists of social phenomena outside the individual social actor, such as their forms of interaction, modes of cooperation (like in formal organisations, but also in informal), and phenomena as shared implicit and explicit perceptions, rules and norms, and as an aggregate of these cultures. From a more dynamic point of view, one can look at the evolution, change and transfer of such phenomena. Or translating this towards the application of industrial ecology, what happens if proponents of industrial ecology suggest the implementation of industrial ecology practices as mentioned in Section 3: how they will be perceived forms the existing shared perceptions and experience-based routines in practice. How will world view-based routine-embedded reflexive social beings, working in the context of specific determining but reflexive organisational constraints, respond to such new impulses?

Finally, we need an analysis at the macro level of societies, addressing the processes of change and consolidation of the aggregate structure of societies and looking for regularities ('laws') in these developments. Also at this level, we can see a balance between statics (conserving existing structures and cultures) and dynamics (continuous changes in society). This level is of course of special interest to those in quest of a sustainable society. Here one looks for answers to questions such as who, or which groups, can get going the process of sustainable development? What explains the level of success of such processes? 
To understand this, we have to recall that individual social beings adapt reflexively to shared experiences as supplied by society, but that these experiences develop thanks to inputs from other social actors or from formalised forms of cooperation. What are the origins of such newly shared experiences? To answer this (at least in democratic societies), five constituting domains of society are relevant in my view:

1 The domain of government, where power is exercised and interests are negotiated (Fearon, 1998) guided by political, legal, macroeconomic and communicative rationalities

2 The domain of production of goods for meeting the material needs of society, using economic rationality within an institutionalised market

3 The domain of science, producing new knowledge, using logic and a positivist rationality, but structured by many disciplines and with various competing paradigms

4 The domain of civil society as organised public discourse and joint-interest cooperation guided by communicative rationality

5 The domain of people, with their diversity in capabilities, psychological characteristics, world views and ambitions, again to be seen as worldview-based routine-embedded reflexive social beings.

In each of these domains, we can see forces of change and forces of conservation. Between these domains we can draw lines of mutual interdependencies. Processes of change will lead to reactions in each of these domains. They may be supportive of sustainable development, but also counteractive. Classical views of policymaking as governing the one-way development of state-induced changes in behaviour of individuals and/or businesses have been replaced by policy theories stressing the mutual dependencies between these spheres of society, requiring 'governance' approaches. Theories on governance stress that governing from a governance perspective always involves an interactive process because no single actor, public or private, has the knowledge and resource capacity to tackle problems unilaterally (Stoker, 1998). Jessop (1998) states that building effective governance mechanisms, amongst other things, requires methods for coordinating actions across different social forces with different identities, interests and meaning systems.

Using this very rough sketch of building stones for a social theory on industrial ecology, we can look at what this would imply for the cross-cutting themes distinguished in Section 3.

1 The first implication was that of firms changing from linear routine practices focusing on short-term profits in business management into multi-goal-oriented strategies capturing the (non-obvious) opportunities of clean production.

For this theme, we are looking at organisations and possibly individuals (very small businesses). We need to understand processes of changing practical routines and management styles within firms, how they have been constructed as a mode of dealing with intraorganisational problems and demands and challenges coming from their societal context. Changes in these routines require a process of reflexive adaptation of proposed sustainable innovations and still need to meet 
intraorganisational problems, requirements and external demands and challenges. Studying how businesses deal or cannot deal with these challenges shows us what can be expected in practice from industrial ecology innovations.

2 The second implication was that of firms accepting and using (processed, former) waste streams, often portrayed as an obvious and often cost-saving solution. In practice, people's perceptions towards reuse are often negative, stressing risks of contamination and quality losses. Businesses are often confronted in market relations and by governmental standards with ample specified requirements and risk-avoiding strategies. Thus the reuse of waste streams is perceived more as an unwanted risk than as desirable salvation. This does not need to be an insurmountable barrier, but at the least it will cost actors from the domains of governing, production or science much time and energy to eliminate such barriers.

3 The third implication was that we should not analyse the implementation of industrial ecology as a single-actor activity, but as forms of multi-actor cooperation.

Cooperation between social beings and organisations is of course nothing new or special. But we need to understand what factors explain the level of progress in the creation of new forms of cooperation. Generally, they will replace or compete with existing routine and experience-based forms of cooperation. The existing forms have proven to be advantageous, whereas the new forms of industrial ecology cooperation generally are still uncertain, not yet fully crystallised and need extra time and investments to be developed.

4 The fourth implication was that implementation of industrial ecology mostly implies processes of innovation and adoption. As we saw, some scholars of industrial ecology are very optimistic about this, suggesting that it will automatically follow S-shaped curves (see Section 3). Innovation studies have made at least one thing clear: most innovations do not succeed at all. In looking for explanations of the rate and speed of adopting innovations, one has to include an analysis of all three levels of society discussed above. Adoption can be seen as decisions made by social beings or organisations, with their characteristics, and addressed by various other actors from society (suppliers, government, advisors, clients, consumers, NGOs, etc.) (Dieperink et al., 2004). Other studies focus on the meso level and macro level of society, looking at what is called 'the innovations system or network' to analyse the speed and rate of development and adoption of innovations (Foray and Grübler, 1996; Freeman, 1996) .

5 The fifth implication was that implementation of industrial ecology implies simultaneous processes, all addressing the same actors. Looking from the perspective of businesses, society (again: suppliers, government, advisors, clients, consumers, NGOs, etc.) addresses them with many policy and issue agendas, even if we restrict our observations to environmental issues: in most countries many different government agencies (at various levels) are each implementing different parts of the environmental agenda, resulting in competing claims and agendas. Businesses will choose their priorities, looking for efficient solutions and possibilities to respond to various external pressures simultaneously, within the given time and budget limitations. 
6 The sixth implication was that of mutual competition between the industrial ecology agenda items, calling for businesses to make choices. This implies that businesses will need appropriate decision-making tools to enable them to make well-informed choices between, for example, recycling or applying new 'green' materials. However, it also calls for natural scientists addressing these issues of mutual competition.

In the next sections, I will apply the line of reasoning shown here for two of the agenda items discussed in Section 3. In both cases, as in the other agenda items, we can see some progress, but certainly slower than what some of the industrial ecology literature is suggesting.

\section{Case 1: creating eco-industrial parks}

The creation of eco-industrial parks has been a very popular issue, ever since the system of physical exchanges in the Danish city of Kalundborg has been documented (Korhonen, 2001; Singhal and Kapur, 2002; Snakin and Korhonen, 2002; Baas and Boons, 2004; Roberts, 2004). With the study of Ehrenfeld and Gertler, we have seen that the creation was actually a spontaneous, some might even call it organically grown, but certainly not top-down-planned process (Ehrenfeld and Gertler, 1997). Yet it has led many to design processes of implementation with a knowledge-driven rational approach (Cote, 1997; Grant, 1997; Lowe, 1997), while some even suggest doing it with some force (Ayres and Ayres, 1996, p.271, p.290). As stated in the Introduction, about 15 years later, we see a meagre practice despite many efforts, which should make us wonder.

We will not understand this obstinate reality if we stick to the model of rational single actors, who should sooner or later see the ample win-win opportunities lying around in industrial parks. The Netherlands may serve as an example here. The Ministries of Economic Affairs and of Environment took up this promising issue in the mid-1990s. Ten years and approximately 200 subsidised eco-industrial park projects later, but only a small number of Kalundborg look-alikes later, the issue has almost been put in the garbage can.

In various studies, we have looked into the practice of implementation of eco-industrial parks. These studies show varying roles of governments in supporting the establishment of exemplary cases, both in The Netherlands and elsewhere. In a comparison of Dutch and US cases, we showed that different approaches have been taken, some strongly relying on the production of full knowledge on waste streams and options for symbiosis. In these cases, the major actors have been local and federal governments and knowledge institutes, but in all these cases there have been problems with involving businesses themselves (Cohen-Rosenthal and Musnikow, 2003; Heeres et al., 2004). Dutch cases show a stronger role for businesses and forms of business cooperation at industrial parks. This has led to the identification of many possible forms of symbiotic cooperation, but only a few of them have actually been put into practice (Eilering and Vermeulen, 2004).

In other Dutch cases, with strong government-led initiatives, getting down to business also seems to be a very difficult task. This may be very surprising, given the approximately 200 cases of eco-industrial park projects in The Netherlands. But most of 
those projects have been restricted to initiation projects, allowing local governments and consultants to start processes of sounding out possible cooperation or technical feasibility studies, but not crossing the line of actual implementation.

This development brings us to the relevance of strategies (phrasing it from a voluntaristic perspective) or sociopolitical processes of implementation (phrasing it from a social science analytical perspective): governments use a specific sequence and mix of policy projects and instruments to promote the application of this type of socioenvironmental innovations. In The Netherlands this includes information campaigns, centres of expertise, subsidies for first mover projects, and bringing together local authorities, experts and business organisations. In a later stage, the issue has been promoted by integrating it into other environmental policy agendas (bringing it up as a subject in various voluntary agreements with industries), thus linking it to competing policy agendas.

When a government supports the implementation of the Eco-Industrial Park concept, two things happen: first, relevant actors have to accept and reinterpret the concept into their own social reality and second; specific actors get a leading role in the advancement of the issue. In the Dutch situation, the introduction of the subsidy scheme opened up a new market for a group of consultancy firms active in the field of environment and business on one hand and in the field of urban planning, industrial estate planning and management on the other hand. On entering this market, many of these developed their own eco-industrial park planning methodologies, selling these to either local authorities or industrial park associations. In this process of reinterpretation, consultancy firms did two things: they twisted the concept into directions in which they possessed a strong knowledge base, and towards practical options they assumed their clients would perceive as feasible. This resulted in an emphasis on other issues with less difficult implementation. In another study (Leeuwen et al., 2003), we analysed the methodologies and showed how the content of the concept of eco-industrial parks shifted away from the original Kalundborg model, based on symbiosis and utility sharing, to other forms of cooperation on industrial parks and even issues not requiring interfirm cooperation at all (such as applying sustainable construction options or sustainable maintenance of common green grounds, which is a municipality task in The Netherlands).

Seeing this deflation effect of the policy strategy, we studied some of the more recent examples of eco-industrial parks which did include symbiosis and utility-sharing options and that followed the first strongly supported exemplary cases, like the INES project (see Baas and Boons, 2004), to find out how they emerged, how the policy had been supportive and how interaction and cooperation between the relevant actors in the implementation process actually evolved. This study (Eilering and Vermeulen, 2004) showed that in these successful cases, the step to actual practising of these forms of interfirm cooperation is still hard to take. Some local governments designed sophisticated methods for allocating new businesses, but were not able to actually attract new firms. One of the most remarkable outcomes of this study was that in those eco-industrial parks where symbiosis and utility sharing were actually applied, these linked-up firms actually already knew each other for a long time and in some cases were firms split up from former parent companies. This proves the extreme importance of creating mutual trust in these types of relations. 
The most recent study we did focused on existing symbiosis cases in The Netherlands. Though very hard to find, we identified ten of those interfirm linkages. Every case has its own typical history of creating this cooperation, but one feature here came out very clearly: in all but one of these cases, the cooperation was initiated and established by companies with a high level of environmental management system in place (all with ISO 14001 certificates). This indicates that starting up interfirm, or beyond that, full-range eco-industrial park cooperation, is a job for firms in the 'master class' of environmental performance. After identifying the opportunities and gaining experience with their symbioses, these firms were convinced and have started looking for other possibilities for such linkages in other parts of their business, so one may expect a process of further diffusion here (Hansen et al., 2005).

Looking at these experiences, what do they teach us with respect to the analysis of the various levels of society? As illustrated in the previous paragraph, we see at the micro level of individual firms relevant differences between front-runners and mainstream firms. Most mainstream firms have a hard job of recognising eco-industrial park and symbiosis opportunities as something relevant for them. They may be locked in routines ignoring environmental impacts and opportunities. But moreover, stepping into environment-oriented partnerships implies taking risks and uncertainties beyond their span of interest. The point to make here is that in such a situation, the originally suggested top-down, knowledge-supply-driven approach, bringing together as many candidates as possible to join the Kalundborg look-alikes, is not likely to be a very successful strategy.

Taking the argument to the meso level, we can look at the networks of interacting firms, government agencies and consultants. We have to recognise that a linear model of knowledge transfer from science towards the domain of production (supported by governments) does not hold. In these relations all actors make reinterpretations of the message of industrial ecology. We have seen that despite the many cases discussed in scientific literature, in the practice of businesses and in government-supported advice the real win-win claim turns out not to be convincing enough yet. This hampers the change of routines of many mainstream firms.

At the macro level, such types of analyses may be used to describe the roles taken by actors in the five domains of society and how various forms of cooperation and long-run governance styles may explain differences in success in implementing eco-industrial parks. Phrasing it like this, answering such questions requires comparative analysis of strategies in various countries. This is a challenging approach, but was beyond the scope of my research until now.

\section{Case 2: innovation processes and sustainable building}

The second case, presented to illustrate the usefulness of the presented elements of a social theory on industrial ecology, combines one of the agenda items (Section 3), the (re)design of the built environment, with one of the cross-cutting themes: processes of adoption of innovation. Sustainable building has developed into a complete field of knowledge in the last decade, ranging from ecologist-inspired forms of 'natural houses' (Graham, 2003) to science-driven systematic efforts to create low-impact buildings, integrating many of the industrial ecology issues discussed in Section 3 (low-impact material, renewable energy, sustainable products) (Anink et al., 1996). With buildings as 
composites of many products, this relates to an overwhelming array of technological solutions. The diffusion of these innovations is a subject of government policies, but also implies active dissemination strategies employed by many other actors (Guy and Moore, 2005). To analyse the processes of change, we first have to look at the nature of societal processes of (re)design and development of the built environment.

Creation of the built environment is, in most countries, a process completely opposite the image of a collection of rational-acting nuclei. It should be described as a political process in a very complex setting with many groups of interdependent actors (architects, project developers, construction firms, suppliers, land owners, consultants, governmental agencies as various levels responsible for land-use planning and construction permits, financiers, social-housing corporations, etc., etc.) (Moss et al., 2005).

In the Dutch situation, the production of dwellings has long been focused on huge numbers of new dwellings, with strong positions held by project developers, social housing corporations and municipal authorities. The position of consumers has been very weak, competing with many others for the low number of houses built by the above-mentioned actors. This description serves to illustrate the point that dissemination strategies should be clearly designed to fit in with this multi-actor situation and with the fact that merely assessing innovations on their economic performance (as assessed by individual rational-acting nuclei) does not teach us much about their chances in practice.

In this complex situation, the Dutch government has strongly promoted sustainable building policies in the last two decades. The overall strategy includes support of research and development and market introduction, regulatory and interactive approaches and the introduction of quality assessment instruments. Comparing it with the promotion of eco-industrial parks, it has clearly been more successful, although clearly even more is possible (van der Waals, 2001; van der Waals et al., 2003).

The existing multi-actor and multi-level situation has been addressed with a mixture of consensual, regulatory and financial strategies. In an early study, we showed that in various regions, various approaches have been taken, varying from top-down to interactive multi-level co-production styles (van der Waals and Vermeulen, 2000). Yet in all cases various newly available innovations tended to be ignored, or when originally taken up as part of the original plans, 'dropped out' during the complex process of creation of the built environment. One might label this as "messy policies taking a long time to establish and poorly implemented", but that would be too simple, ignoring the complex nature of these processes.

One of the approaches we tested was improving collaborative planning processes and improving the knowledge transfer about the ongoing flow of innovations in this sphere to a broader collection of stakeholders involved in the various stages of creating the planned environment. As we showed with these experiments, such participative approaches may lead to higher levels of ambition and stakeholder commitment in complex planning processes (van der Waals and Vermeulen, 2002).

In another study, we focused on the decision-making processes in construction projects for office buildings and analysed which factors explain the factual adoption of a number of energy innovations. Such projects work with strong time constraints and routine-based divisions of tasks in a context of many public and private stakeholders with their specified demands, requirements and procedures. In this social context, local and national government agencies try to compel constructors into using new technologies, 
which they do not yet know (such as high-efficiency glazing, hot and cold storage, high-efficiency lighting and high-efficiency heating systems). In this study, we tested a theoretical framework developed to integrate the many possible explanations of a firm's responses to innovations, representing variables at both micro, meso and macro levels (see Dieperink et al., 2004). This theoretical framework connects intrafirm decision-making practices and multiple assessment criteria used in decision making with organisational features and interactions with the external societal environment (with governments, markets, advisers, public debates, etc.). This study shows that adoption behaviour (partial adoption of the four technologies) cannot fully be understood as a result of their rational decision making. The level of adoption can be better explained if we include variables describing how these project developers structure their decision-making process (ranging from synoptic rational assessments to routine-based decisions without any inquiry into possible alternatives). This mode of decision making proves to correlate mainly with how well these firms have (voluntarily) organised their environmental management practices.

Without going into further details of this analysis, we can say here that it teaches us much about routines, about possible ways to burst through these robust experience-based modes of working which prevent businesses from basing any decision on fully informed, rational assessments. It also makes a point for identifying differences within specific target groups of specific policies. In the case of these office construction projects, the front-running project developers made very different assessments of the innovations from those who did not seriously investigate their options. The study also showed the poor impacts of informational instruments used, but the strong impact of a new flexible system of energy performance standards applied in this field (Vermeulen and Hovens, 2006).

\section{Concluding remarks}

In the last decades, various authors have called for more input from social sciences in industrial ecology. In most cases, they see a role for social sciences in providing recipes for implementation, supporting policymakers or managers. In this paper, I showed that the assignment of this normative role is rooted in a rather simple image of how society works. Yet a few examples are available of authors setting the first steps in building theory on the social dimension of industrial ecology (such as Andrews, Reinhardt, Cohen-Rosenthal, Esty and Porter, Fishoff and Small).

In this paper, I pushed the line of reasoning beyond this, taking essential elements of sociological theory to create at least a skeleton of what might be a theory on the social dimension of industrial ecology (or if one wishes to label it more broadly: a theory of social change towards a sustainable society). Such a theory should contain reflections on the connections between micro-level, meso-level and macro-level analysis. I discussed some of the many relevant issues here and left out many others. The issues presented are all linked to the implementation of industrial ecology practices and the often-hampered mainstreaming of these.

In many countries, programmes have been developed and implemented to disseminate the six types of practical implications of industrial ecology. The successes and failures in these processes of societal change offer social scientists fertile ground 
to analyse societal change in practice. In this way they can go beyond prescriptive and normative theories, often based upon the notion of economically rational individual actors.

One may improve the image of economic actors, as Esty and Porter and also Andrews have done, by showing relevant theories from the fields of institutional and evolutionary economy and organisational and management sciences. But in my view there is a need for more. ${ }^{5}$

In the two exemplary cases discussed in Sections 7 and 8, I showed that for proper understanding, other building blocks of a theory on the social dimension should be taken into consideration, including social science concepts addressing the three levels of society.

The distinction between individual actors and organisations, as also suggested by Andrews, is a first step. It allows us to look at specific roles of various individuals in organisations, and also to look at specific features of organisations themselves. The complementary focus on internal motivators and external conditions allows us to look at both individuals and organisations as social objects that are self-directing but also adjusting to changing circumstances in their social and physical environments.

At the individual, the organisational and the interorganisational levels, as we have shown, the processes for making decisions are crucial for the change towards the world modelled by industrial ecologists. After having provided methods and models for 'rational decision making', we have to focus on the decision making in practice, learning from the differences between the prescriptive, normative theory and the world in practice. This does not imply that people and organisations cannot benefit from these models, but for full diffusion of industrial ecology innovations, we need to understand barriers, objections and unexpected deviations. This may help to identify smarter strategies, and smarter innovations.

We should also acknowledge that social objects are not a homogeneous group in this; they have diverging views of and responses to their social environment, and this leads to diverging strategies being taken. Looking at social objects as entities with multiple interactions with other social objects is essential here: both individuals and organisations develop strategies to survive the overload of information, social demands and legal obligations they have to cope with. Some may take the role of being in the lead, others may choose a more reactive approach, having the advantage of learning from the mistakes of the front-runners (we described differences between various groups of front-runners in a recent article; see Runhaar et al., 2006).

Taking the analysis even beyond the intrafirm focus, we have to look at the meso level and macro level as well. Linking individual social objects to their social environments brings us to the issue of interfirm cooperation, which is very relevant because most practices of industrial ecology are of this nature, as shown in Section 3. Multiple-actor cooperation brings in an extra dimension of gaining trust (which may result in losing flexible business-to-business relations) and the need for analysing possible explanations for the levels of success of various modes of interaction and cooperation. Issues to analyse are how these may contribute to newly shared views and rules of conduct. These are not mono-directional processes (from science towards individuals or firms); various actors in society participate in the processes of creation of shared views and rules. In this sense, the formulation of the practical imperatives of industrial ecology and responses from society are relevant objects of study. 
At the macro level, we just showed some possible fields of work. Here it is useful to analyse how implementation is structured in the forms of cooperation, linking the |most relevant domains of society (domains of government, production and consumption systems, development and application of sciences, civil society as the organised social discourse, and finally the domain of individual people).

With this call for more social science input, I intend to go beyond the more instrumental role often assigned to social sciences, which focuses on supplying quantitative data (consumption and land use) and policy advice. This paper explicitly reflects upon literature available in the field of industrial ecology. One final remark needs to be made here: the observation that analysis of the social dimension of industrial ecology is weakly developed is consciously biased by this focus. I have ignored various other scientific communities and bodies of knowledge (sociologists, business management, organisation studies, policy scientists, sociologists of law, innovation studies, transdisciplinarity, planning studies, international relations, psychologists, etc.) that have been doing work largely overlapping the same field of practice, but not labelling this as industrial ecology. Linking the work of industrial ecology to these other relevant scientific communities is a challenging assignment.

\section{References}

Allenby, B.R. (1992) 'Industrial ecology - the materials scientist in an environmentally constrained world', Materials Research Society Bulletin, Vol. 17, No. 3, pp.46-51.

Andrews, C.J. (2001) 'Building a micro foundation for industrial ecology', Journal of Industrial Ecology, Vol. 4, No. 3, pp.35-51.

Anink, D., Boonstra, C., et al. (1996) Handbook of Sustainable Building: An Environmental Preference Method for Selection of Materials for Use in Construction and Refurbishment, London: James and James.

Ayres, R.U. (1989) 'Industrial metabolism and global change', International Social Science Journal, Vol. 41, No. 3, pp.363-373.

Ayres, R.U. and Ayres, L. (1996) Industrial Ecology: Towards Closing the Materials Cycle, Cheltenham, UK/Brookfield, VT: Edward Elgar.

Baas, L.W. and Boons, F.A. (2004) 'An industrial ecology project in practice: exploring the boundaries of decision-making levels in regional industrial systems', Journal of Cleaner Production, Vol. 12, Nos. 8-10, pp.1073-1085.

Boons, F. and Roome, N. (2001) 'Industrial ecology as a cultural phenomenon - on objectivity as a normative position', Journal of Industrial Ecology, Vol. 5, No. 1, pp.49-54.

Cagno, E., Trucco, P., et al. (2005) 'Cleaner production and profitability: analysis of 134 industrial pollution prevention (P2) project reports', Journal of Cleaner Production, Vol. 13, No. 6, pp.593-605.

Cohen-Rosenthal, E. (2000) 'A walk on the human side of industrial ecology', American Behavioral Scientist, Vol. 44, No. 2, pp.245-264.

Cohen-Rosenthal, E. and Musnikow, J. (2003) Eco-industrial Strategies: Unleashing Synergy Between Economic Development and the Environment, Sheffield: Greenleaf.

Cote, R. (1997) 'Industrial ecosystems and eco-industrial parks, industrial ecosystems: evolving and maturing', Journal of Industrial Ecology, Vol. 1, No. 3, pp.9-11.

Cramer, J. (1996) 'Experiences with implementing integrated chain management in Dutch industry', Business Strategy and the Environment, Vol. 5, No. 1, pp.38-47. 
Daly, H.E. (1990) 'Toward some operational principles of sustainable development', Ecological Economics, Vol. 2, No. 1, pp.1-6.

Dieperink, C., Brand, I., et al. (2004) 'Diffusion of energy-saving innovations in industry and the built environment: Dutch studies as inputs for a more integrated analytical framework', Energy Policy, Vol. 32, No. 6, pp.773-784.

Ehrenfeld, J.R. (1992) 'Industrial ecology - a technological approach to sustainability', Hazardous Waste \& Hazardous Materials, Vol. 9, No. 3, pp.209-211.

Ehrenfeld, J.R. (1997) 'Industrial ecology: a framework for product and process design', Journal of Cleaner Production, Vol. 5, Nos. 1-2, pp.87-95.

Ehrenfeld, J.R. (2000) 'Industrial ecology: paradigm shift or normal science?', American Behavioral Scientist, Vol. 44, No. 2, pp.229-244.

Ehrenfeld, J.R. and Gertler, N. (1997) 'Industrial ecology in practice: the evolution of interdependence in Kalundborg', Journal of Industrial Ecology, Vol. 1, No. 1, pp.67-79.

Eilering, J.A.M. and Vermeulen, W.J.V. (2004) 'Eco-industrial parks: establishing symbiosis and utility sharing in practice', Progress in Industrial Ecology, Vol. 1, Nos. 1-3, pp.245-270.

Elkington, J. (1994) 'Towards the sustainable corporation - win-win-win business strategies for sustainable development', California Management Review, Vol. 36, No. 2, pp.90-100.

Erkman, S. (1997) 'Industrial ecology: an historical view', Journal of Cleaner Production, Vol. 5, Nos. 1-2, pp.1-10.

Erkman, S. (2002) 'The recent history of industrial ecology', in R.U. Ayres and L. Ayres (Eds.) A Handbook of Industrial Ecology, Cheltenham, UK/Northampton, MA: Edward Elgar Pub., pp.27-35.

Esty, D. and Porter, M. (1998) 'Industrial ecology and competitiveness: strategic implications for the firm', Journal of Industrial Ecology, Vol. 2, No. 1, pp.35-44.

Fearon, J.D. (1998) 'Democracy and deliberation', Deliberate Democracy, in J. Elster (Ed.) Cambridge: Cambridge University Press, pp.44-68.

Fischhoff, B. and Small, M.J. (1999) 'Human behavior in industrial ecology modeling', Journal of Industrial Ecology, Vol. 3, Nos. 2-3.

Fisher-Kowalski, M. (2002) 'Exploring the history of industrial metabolism', R.U. Ayres and L. Ayres (Eds.) A Handbook of Industrial Ecology, Cheltenham, UK/Northampton, MA: Edward Elgar Pub., pp.16-26.

Foray, D. and Grübler, A. (1996) 'Technology and the environment: an overview', Technological Forecasting and Social Change, Vol. 53, No. 1, pp.3-13.

Freeman, C. (1996) 'The greening of technology and models of innovation', Technological Forecasting and Social Change, Vol. 53, No. 1, pp.27-39.

Frosch, R.A. (1992) 'Industrial ecology - a philosophical introduction', Proceedings of the National Academy of Sciences of the United States of America, Vol. 89, No. 3, pp.800-803.

Frosch, R.A. and Gallopoulos, N.E. (1989) 'Strategies for manufacturing', Scientific American, Vol. 261, No. 3, pp.144-153.

Giddens, A. (1993) New Rules of Sociological Method: A Positive Critique of Interpretative Sociologies, Stanford, CA: Stanford University Press.

Graedel, T.E. (2000) 'The evolution of industrial ecology', Environmental Science \& Technology, Vol. 34, No. 1, pp.28A-31A.

Graedel, T.E. and Allenby, B.R. (1995) Industrial Ecology, Englewood Cliffs, NJ: Prentice Hall.

Graham, P. (2003) Building Ecology. First Principles For A Sustainable Built Environment, Oxford: Blackwell Science Publishing.

Grant, J. (1997) 'Planning and designing industrial landscapes for eco-efficiency', Journal of Cleaner Production, Vol. 5, Nos. 1-2, pp.75-78. 
Guy, S. and Moore, S.A. (Eds.) (2005) Sustainable Architectures: Cultures and Natures in Europe and North America, New York/London: Spon Press.

Hansen, D.H.J.M., Lavrijsen, T., et al. (2005) 'Duurzame industriële samenwerking loont! Praktijkonderzoek naar de economische en ecologische voordelen van industriële samenwerkingsverbanden (Sustainable industrial cooperation pays!)', Arena Het Dossier, Vol. 11, No. 8, pp.117-120.

Harré, R. (1993) Social Being, Oxford, UK/Cambridge, USA: Blackwell.

Heeres, R.R., Vermeulen, W.J.V., et al. (2004) 'Eco-industrial park initiatives in the USA and The Netherlands: first lessons', Journal of Cleaner Production, Vol. 12, Nos. 8-10, pp.985-995.

Huisingh, D. and Bailey, V. (1982) Making Pollution Prevention Pay: Ecology with Economy as Policy, New York: Pergamon Press.

Huisingh, D., Martin, L.R., et al. (1986) Proven Profits from Pollution Prevention: Case Studies in Resource Conservation and Waste Reduction, Institute for Local Self-Reliance, Washington, DC.

Jessop, B. (1998) 'The rise of governance and the risks of failure: the case of economic development', International Social Science Journal, Vol. 50, No. 1, pp.29-45.

Kogg, B. (2003) 'Power and incentives in environmental supply chain management', in S.A. Seuring, M. Müller, M. Goldbach and U. Schneidewind (Eds.), Strategy and Organization in Supply Chains, Heidelberg: Physica Verlag, pp.65-82.

Korhonen, J. (2001) 'Regional industrial ecology: examples from regional economic systems of forest industry and energy supply in Finland', Journal of Environmental Management, Vol. 63, No. 4, pp.367-375.

Korhonen, J. (2004) 'Theory of industrial ecology', Progress in Industrial Ecology, Vol. 1, Nos. 1-3, pp.61-88.

Leeuwen, M.G.v., Vermeulen, W.J.V., et al. (2003) 'Planning eco-industrial parks: an analysis of Dutch planning methods', Business Strategy and the Environment.

Lifset, R. and Graedel, T.E. (2002) 'Industrial ecology: goals and definitions', in R.U. Ayres and L. Ayres (Eds.) A Handbook of Industrial Ecology, Cheltenham, UK/Northampton, MA: Edward Elgar Pub., pp.3-15.

Lowe, E.A. (1997) 'Creating by-product resource exchanges: strategies for eco-industrial parks', Journal of Cleaner Production, Vol. 5, Nos. 1-2, pp.57-65.

Mann, D. and Jones, E. (2002) 'Sustainable Services Systems (3s) through systematic innovation methods', Journal of Sustainable Product Design, Vol. 2, No. 3, pp.131-139.

Moss, T., Slob, A., et al. (2005) 'The politics of design in cities: preconceptions, frameworks and trajectories of sustainable building', in S. Guy and S.A. Moore (Eds.) Sustainable Architectures: Cultures and Natures in Europe and North America, New York/London: Spon Press, pp.73-88.

Nattrass, B. and Altomare, M. (1999) The Natural Step for Business. Wealth, Ecology and the Evolutionary Corporation, Gabriola Island: New Society Publishers.

Nelissen, N.J.M., Klinkers, L., et al. (1998) Classics in Environmental Studies: Overview of Classic Texts in Environmental Studies, Utrecht: International Books.

Quakernaat, J. and Weenk, A. (1993) 'Integrated life cycle management at company level: the concept of environmental merit', Journal of Cleaner Production, Vol. 1, No. 2, pp.99-106.

Robèrt, K-H. (2000) 'Tools and concepts for sustainable development, how do they relate to a general framework for sustainable development, and to each other?', Journal of Cleaner Production, Vol. 8, No. 3, pp.243-254.

Roberts, B.H. (2004) 'The application of industrial ecology principles and planning guidelines for the development of eco-industrial parks: an Australian case study', Journal of Cleaner Production, Vol. 12, Nos. 8-10, pp.997-1010. 
Runhaar, H., Tigchelaar, C., et al. (2006) 'Environmental leaders: making a difference. A typology of environmental leaders and recommendations for a differentiated policy approach', Accepted for publication in Business Strategy and the Environment, http://www3.interscience .wiley.com/cgi-bin/fulltext/112315525/PDFSTART.

Schwarz, M. and Thompson, M. (1990) Divided We Stand: Re-defining Politics, Technology and Social Choice, Hemel Hempstead: Harvester Wheatsheaf.

Singhal, S. and Kapur, A. (2002) 'Industrial estate planning and management in India - an integrated approach towards industrial ecology', Journal of Environmental Management, Vol. 66, No. 1, pp.19-29.

Snakin, J.P.A. and Korhonen, J. (2002) 'Industrial ecology in the North Karelia Region in Finland - scenarios for heating energy supply', International Journal of Sustainable Development and World Ecology, Vol. 9, No. 1, pp.9-21.

Socolow, R.H. (1994) Industrial Ecology and Global Change, Cambridge/New York: Cambridge University Press.

Stern, P.C. (1993) 'A second environmental science: human-environment interactions', Science, Vol. 260, No. 5116, pp.1897-1899.

Sterr, T. and Ott, T. (2004) 'The industrial region as a promising unit for eco-industrial development - reflections, practical experience and establishment of innovative instruments to support industrial ecology', Journal of Cleaner Production, Vol. 12, Nos. 8-10, pp.947-965.

Stoker, G. (1998) 'Governance as theory: five propositions', International Social Science Journal, Vol. 50, No. 1, pp.17-28.

Tellegen, E. and Wolsink, M. (1998) Society and Its Environment, Amsterdam: Gordon and Breach Science Publishers.

Tibbs, H. (1991) Industrial Ecology: A New Environmental Agenda for Industry, A.D. Little and Global Business Network.

van der Waals, J.F.M. (2001) ' $\mathrm{CO}_{2}$-reduction in housing: experiences in building and urban renewal projects in The Netherlands', Faculty of Geography, Department of Environmental Studies and Policy, Utrecht: Utrecht University, p.285.

van der Waals, J.F.M. and Vermeulen, W.J.V. (2000) 'Sustainable building: lessons for local policy processes', Milieu (Journal of Environmental Sciences), Vol. 15, No. 2, pp.103-110.

van der Waals, J.F.M. and Vermeulen, W.J.V. (2002) 'The $\mathrm{CO}_{2}$-reduction workshop: Dutch experiences with a participatory approach', Journal of Environmental Planning and Management, Vol. 45, No. 4, pp.549-569.

van der Waals, J.F.M., Vermeulen, W.J.V., et al. (2003) ' $\mathrm{CO}_{2}$-reduction in housing: experiences in urban renewal projects in The Netherlands', Environment and Planning C: Government and Policy, Vol. 21, No. 3, pp.411-427.

Vermeulen, W.J.V. and Hovens, J. (2006) 'Competing explanations for the adoption of energy innovations: the case of new office buildings', Energy Policy, Vol. 34, No. 17, pp.2719-2735.

Vermeulen, W.J.V. and Ras, P. (2006) 'The challenge of greening global product chains: meeting both ends', Sustainable Development, Vol. 14, No. 4, pp.245-256.

Vermeulen, W.J.V., Kok, M.T.J., et al. (1994) Perspectives on Integrated Chain Management: Options for Policy, Apeldoorn: TNO Policy Research.

White, R. (1994) 'Preface', The Greening of Industrial Ecosystems, in B.R. Allenby and D.J. Richards (Eds.) Washington, DC: National Academy Press.

Wolters, T., James, P., et al. (1997) 'Stepping-stones for integrated chain management in the firm', Business Strategy and the Environment, Vol. 6, No. 3, pp.121-132.

Ytterhus, B.E., Arnestad, P., et al. (1999) 'Environmental initiatives in the retailing sector: an analysis of supply chain pressures and partnerships', Eco-Management and Auditing, Vol. 6, No. 4, pp.181-188. 


\section{Notes}

1 This metaphor has often incorrectly been used as an example of unregulated selfish behaviour of individuals using collective goods as much as possible for their own gain. The empirical history, history of the overexploitation of the commons, to be solved by privatisation, was quite the opposite: small societies employed social rules in the use of commons, but legal changes (enclosure by feudal barons) led to overexploitation and poverty of villagers (see Nelissen et al., 1998; Tellegen and Wolsink, 1998).

2 See Erkman (1997).

3 Note the contrast here with the suggested non-connectedness in the text of Ehrenfeld (see the end of Section 2).

4 Paraphrasing Ehrenfeld (2000, p.231)

5 The argument resembles a point made by P.C. Stern (a member of the Commission on Behavioural and Social Sciences and Education of the US National Research Council) in an article in Science (1993):

“... we need more than plausible scenarios of human behavior. Policy failures repeatedly result from faith in intuitively attractive but mistaken ideas about behavior: that people will accept expert's risk analysis at face value; that firms will accept and fully implement regulations; that consumers will act on relevant information; and that the free market or quasi-market incentives will work in practice as they do in theory. We need a second environmental science - one focused on human-environment interactions - to complement the science of environmental processes by analyzing key questions as these: what forces drive the human activities (...); which interventions are most effective (...)." 